\title{
Association of Pancreatic Insufficiency and Chronic Neutropenia in Childhood
}

\author{
VALERIE BURKE, JOHN H. COLEBATCH, CHARLOTTE M. ANDERSON, \\ and MALCOLM J. SIMONS \\ From the Gastroenterological and Haematological Research Units, Royal Children's Hospital Research Foundation,
Royal Children's Hospital, Melbourne, Australia
}

In childhood, pancreatic exocrine insufficiency is rarely encountered except as one of the features of cystic fibrosis, which is in contrast to the pattern of pancreatic disease in adults, where pancreatitis is common. However, paediatricians recognize that some children with symptoms of pancreatic insufficiency do not have the chronic chest infection and raised levels of electrolytes in the sweat characteristic of cystic fibrosis. Recently Bodian, Sheldon, and Lightwood (1964) have described congenital hypoplasia of the exocrine pancreas in 2 such children. Variable neutropenia and thrombocytopenic purpura occurred in both but did not receive special comment. In 1964 Shwachman, Diamond, Oski, and Khaw reported 5 similar patients, drawing particular attention to the association of haematological and pancreatic abnormalities.

These reports stimulated us to review those of our patients whom we knew to have pancreatic exocrine insufficiency but not the other findings of cystic fibrosis, and those children with so-called idiopathic neutropenia. Two of us (C.M.A. and J.H.C.) had recognized as far back as 1946 one patient with both pancreatic insufficiency and chronic neutropenia, but had not pursued this association. A preliminary report of some of the findings in these patients has been published (Colebatch, Anderson, Simons, and Burke, 1965), but further patients have been encountered since that time.

In all, 19 children have presented with, initially, at least one of these features, and 11 of them have now been shown to have both. Although the syndrome is rare, we consider it to be the major disorder of pancreatic exocrine function of children in whom cystic fibrosis has been excluded.

Associated features are noteworthy in a number of the patients, particularly the radiological changes of metaphysial dysostosis. A familial incidence of the

Received August 15, 1966. syndrome observed by Shwachman et al. (1964) has also occurred. Likewise, the steatorrhoea of some of our patients has decreased considerably as they have grown older, despite persisting absence of pancreatic exocrine secretions.

\section{Material and Methods}

A total of 19 patients initially found to have one of the 2 main features of the syndrome was studied. Of the 19 children, 11 had been investigated primarily for a haematological disorder and shown to have 'idiopathic' chronic neutropenia, arbitrarily defined as repeated neutrophil counts of less than $1500 / \mathrm{c} . \mathrm{mm}$. The remaining 8 were investigated primarily because of symptoms suggesting malabsorption and were shown to have no more than traces of pancreatic enzyme activity in their duodenal contents. Cystic fibrosis had been ruled out in the latter group by demonstrating normal levels of electrolytes in the sweat and the absence of chronic obstructive lung disease.

Of the 19, 11 have now been shown to have both features of the syndrome, i.e. 5 of the 11 presenting with neutropenia and 6 of the 8 presenting with malabsorption.

Full blood examinations were performed on several occasions in all patients studied and wherever possible in the parents and sibs.

Pancreatic function was assessed using specimens of intestinal contents obtained by passing a radio-opaque tube into the duodenum under fluoroscopic control. In every patient lipase, trypsin, and amylase activity was estimated in samples obtained after instilling olive oil into the duodenum (Shwachman and Dooley, 1955). In 3 patients this test was repeated after stimulation with Secretin (Vitrum) and Pancreozymin (Boots). Pancreatic lipase was determined by the method of Nothman, Pratt, and Benotti (1948), using olive oil as a substrate. Trypsin was estimated with azo-albumin as the substrate (Tomarelli, Charney, and Harding, 1949), and the method of Free and Myers (1943) was employed for amylase determination.

Microscopy of the stools for fat globules was carried 
TABLE I

Clinical Features of 11 Patients Known to Have Pancreatic Insufficiency and Neutropenia

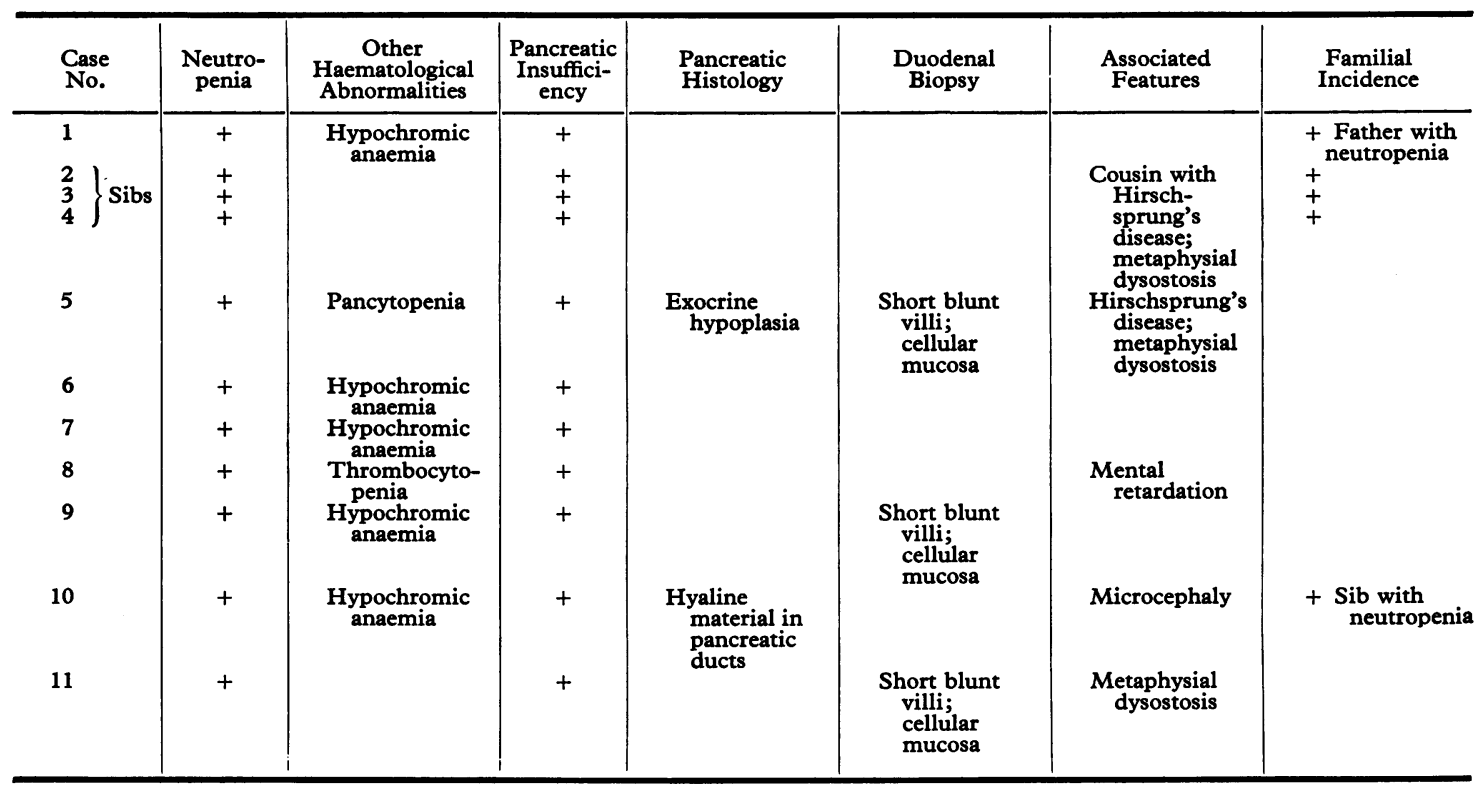

$+=$ present.

out, and faecal fat excretion determined quantitatively from stool collections for at least 3 days on each patient. Faecal fat was estimated by a method similar to that of Van de Kamer, ten Bokkel Huinink, and Weyers (1949), and steatorrhoea was considered to be present if the faecal fat averaged more than $5 \mathrm{~g}$./day during the period of the balance, with the intake of fat between 40 and $50 \mathrm{~g}$.

Duodenal biopsy using the Crosby capsule (Crosby and Kugler, 1957) was obtained in 3 children, and in one boy with associated Hirschsprung's disease a biopsy of the pancreas was taken later at laparotomy.

Bone-marrow aspiration was performed in 8 of the 11 children found to have both neutropenia and pancreatic insufficiency.

\section{Results}

Three of the patients in the group presenting primarily with neutropenia have not so far been available for adequate pancreatic investigations. Among these, of the original 19 who have been investigated completely (i.e. 16), 11 patients had both neutropenia and pancreatic insufficiency, 3 patients with neutropenia had normal levels of pancreatic enzymes, while 2 patients had pancreatic insufficiency without neutropenia but with diabetes mellitus.

Further discussion will be limited to the 11 children ( 6 girls and 5 boys) found to have both pancreatic insufficiency and neutropenia. The case histories of these patients are summarized in the Appendix, and Table I indicates their main clinical features. Table II gives the results of the gastrointestinal and haematological investigations.

Among the 6 patients of this 11 who presented primarily with symptoms of malabsorption, abnormal stools were noticed from the first week of life in 2 children but appeared in the other 4 only after weaning. One of these children (Case 9) presented at the age of 14 months with meningitis and pneumonia; minor infections were common in the other patients of this group.

Among the children initially found to have neutropenia (Case 6,7, 10), infections were more severe and symptoms of malabsorption less prominent. Case 6 died at the age of 4 years and 10 months, following recurrent empyema and a chronic liver abscess. Persistent chest infection led to the death of Case 10, and her neutropenic sib had died with septicaemia. Chronic otitis media with mastoiditis was a problem in Case 7 which was the only one of these 3 children with a history of diarrhoea.

Gastro-enterological features. Steatorrhoea, with a daily fat excretion of more than $5 \mathrm{~g}$., was found in 9 of the 11 patients (Table II). The amount of fat excreted was greater in the younger 
TABLE II

Investigations in 11 Patients With Pancreatic Insufficiency and Neutropenia

\begin{tabular}{|c|c|c|c|c|c|c|c|c|c|}
\hline \multirow{3}{*}{$\begin{array}{l}\text { Case } \\
\text { No. }\end{array}$} & \multirow{3}{*}{$\begin{array}{c}\text { Date } \\
\text { of } \\
\text { Test }\end{array}$} & \multicolumn{5}{|c|}{ Gastro-enterological } & \multicolumn{3}{|c|}{ Haematological } \\
\hline & & \multicolumn{3}{|c|}{$\begin{array}{l}\text { Units of Pancreatic Enzyme } \\
\text { Activity }\end{array}$} & \multirow{2}{*}{$\begin{array}{c}\text { Faecal } \\
\text { Fat } \\
\text { (g./day) }\end{array}$} & \multirow{2}{*}{$\begin{array}{c}\text { Fat } \\
\text { Intake } \\
(\mathrm{g} / \text { day })\end{array}$} & \multirow{2}{*}{\multicolumn{2}{|c|}{ Neutrophils (range/c.mm.) }} & \multirow{2}{*}{ Bone-marrow } \\
\hline & & $\begin{array}{l}\text { Lipase } \\
N: 2-6\end{array}$ & $\begin{array}{c}\text { Trypsin } \\
\mathrm{N}: 10-60\end{array}$ & $\begin{array}{l}\text { Amylase } \\
\mathrm{N}: 2-10\end{array}$ & & & & & \\
\hline 1 & 1948 & Nil & $\mathrm{Nil}$ & $\mathrm{Nil}$ & $\begin{array}{l}42 \% \\
\text { dried }\end{array}$ & 50 & $80-7200$ & Monocytosis & Normal \\
\hline 2 & $\begin{array}{l}1957 \\
1964 \\
1955\end{array}$ & $\begin{array}{l}\mathrm{Nil} \\
0 \cdot 2 \\
\mathrm{Nil}\end{array}$ & $\begin{array}{l}\mathrm{Nil} \\
0 \cdot 6 \\
\mathrm{Nil}\end{array}$ & $\begin{array}{l}\mathrm{Nil} \\
\mathrm{Nil} \\
\mathrm{Nil}\end{array}$ & $\begin{array}{c}\text { weight } \\
20 \\
5 \\
15\end{array}$ & $\begin{array}{l}40 \\
55 \\
38\end{array}$ & $532-2765$ & Eosinophilia & Not tested \\
\hline 3 & $\begin{array}{l}1960 \\
1964\end{array}$ & $\begin{array}{l}1 \cdot 0 \\
\mathrm{Nil}\end{array}$ & $\begin{array}{l}0.5 \\
\mathrm{Nil}\end{array}$ & Nil & & 40 & $651-1250$ & Eosinophilia & Not tested \\
\hline 4 & $\begin{array}{l}1964 \\
1961\end{array}$ & $\begin{array}{l}\text { Nil } \\
\text { Nil }\end{array}$ & Nil & Nil & & $\begin{array}{l}35 \\
35 \\
55\end{array}$ & $140-810$ & Monocytosis & Not tested \\
\hline 5 & $\begin{array}{l}1965 \\
1966\end{array}$ & $\begin{array}{l}\text { Nil } \\
\text { Nil }\end{array}$ & $\begin{array}{l}\text { Nil } \\
\text { Nil }\end{array}$ & $\begin{array}{l}\text { Nil } \\
\text { Nil }\end{array}$ & $\begin{array}{r}20 \\
7\end{array}$ & $\begin{array}{l}60 \\
70\end{array}$ & $216-2265$ & Pancytopenia & Hypocellular \\
\hline $\begin{array}{r}6 \\
7 \\
8 \\
9 \\
10 \\
11\end{array}$ & $\begin{array}{l}1965 \\
1965 \\
1965 \\
1965 \\
1965 \\
1966\end{array}$ & $\begin{array}{l}0 \cdot 2 \\
\mathrm{Nil} \\
\mathrm{Nil} \\
0 \cdot 3 \\
0 \cdot 3 \\
\mathrm{Nil}\end{array}$ & $\begin{array}{l}\mathbf{0} \cdot 8 \\
\mathrm{Nil} \\
\mathrm{Nil} \\
\mathrm{Nil} \\
\mathrm{Nil} \\
\mathrm{Nil}\end{array}$ & $\begin{array}{l}1 \cdot 8 \\
\mathrm{Nil} \\
\mathrm{Nil} \\
\mathrm{Nil} \\
1 \cdot 6 \\
\mathrm{Nil}\end{array}$ & $\begin{array}{l}3 \cdot 5 \\
6 \\
12 \\
40 \\
3 \cdot 5 \\
8\end{array}$ & $\begin{array}{l}25 \\
40 \\
40 \\
50 \\
20 \\
25\end{array}$ & $\begin{array}{c}0-2500 \\
44-1800 \\
0-1145 \\
285-6890 \\
0-184 \\
727-2044\end{array}$ & $\begin{array}{l}\text { Monocytosis, eosinophilia } \\
\text { Monocytosis, eosinophilia } \\
\text { Monocytosis, eosinophilia } \\
\text { Monocytosis, eosinophilia } \\
\text { Monocytosis, eosinophilia } \\
\text { Monocytosis, eosinophilia }\end{array}$ & $\begin{array}{l}\text { Hypocellular } \\
\text { Hypocellular } \\
\text { Hypocellular } \\
\text { Not tested } \\
\text { Hypocellular } \\
\text { Hypocellular }\end{array}$ \\
\hline
\end{tabular}

patients with the exception of Case 10. Fat balance studies were repeated in 3 patients (Cases 2, 3, 5) after an interval of up to 10 years. In each case steatorrhoea had decreased considerably, and in 2 the average excretion of fat was at the upper limit of normal, though pancreatic enzymes could not be demonstrated in the duodenal contents at this time. Steatorrhoea was minimal in Case 7 when first tested at the age of 6 years. Fat excretion was less than $5 \mathrm{~g}$. per day at the initial testing in the remaining 2 patients, but in both of them the fat intake was low during the period of the fat balance study. One was a boy first tested at the age of 5 when the daily intake of fat was $25 \mathrm{~g}$. and the other a female infant having a daily intake of $20 \mathrm{~g}$. fat studied at the age of 3 months. The absorption coefficient was therefore $88 \%$ and $85 \%$, respectively.

In all patients whose daily faecal fat excretion was greater than 5 g., fat globules were seen at some time, on microscopy of the stools. In those patients whose steatorrhoea was shown to decrease with age, fat globules were seen in the stools when these children presented initially, but not at the time when the fat balance studies were repeated and when the steatorrhoea was minimal.

In all patients with pancreatic insufficiency there was no more than a trace of activity of lipase, amylase, or trypsin in duodenal contents, and no particular enzyme was differentially reduced.

In each of the 3 children in whom a biopsy of the small intestine was performed, mild inflammatory changes with blunting of the villi were seen in the mucosa. However, Giardia lamblia infestation was present in Case 5 when the duodenal biopsy was obtained.

The pancreatic tissue obtained at laparotomy in Case 5 showed hypoplasia of the exocrine tissue with apparently normal islets separated by fat, similar to the appearance in the patients described by Bodian et al. (1964). The pancreatic ducts were filled with hyaline material in one patient (Case 10) who came to necropsy at the age of 5 months.

Haematological features. In 7 of these 11 children, the neutrophil count was persistently low, ranging from 0 to 200 cells $/$ c.mm. and contributing only 2 or $3 \%$ of the total leucocytes (Table II). The neutropenia was variable in the other 4 patients, and in 2 of them was cyclical with a periodicity of 21 days. Thrombocytopenia was demonstrated in only 2 children (Cases 5 and 8), but in most of those patients whose platelets appeared normal on examination of a blood film, platelet counts were not performed. Anaemia, which was corrected by the administration of iron, occurred in all but 3 patients (Cases 2, 3, and 4). One patient (Case 5), who developed pancytopenia at the age of 7 , was the only one of the group with hypoplastic anaemia.

Of 8 children in whom bone-marrow aspirations were performed, 6 showed a deficiency of myeloid elements. One of these, Case 8, also showed a deficiency of megakaryocytes. In 2 patients (Cases 1 and 5), with cyclical neutropenia, the bonemarrow showed a preponderance of proliferating myeloid cells when sampled during a phase of neutropenia. That myeloid recovery was occurring 


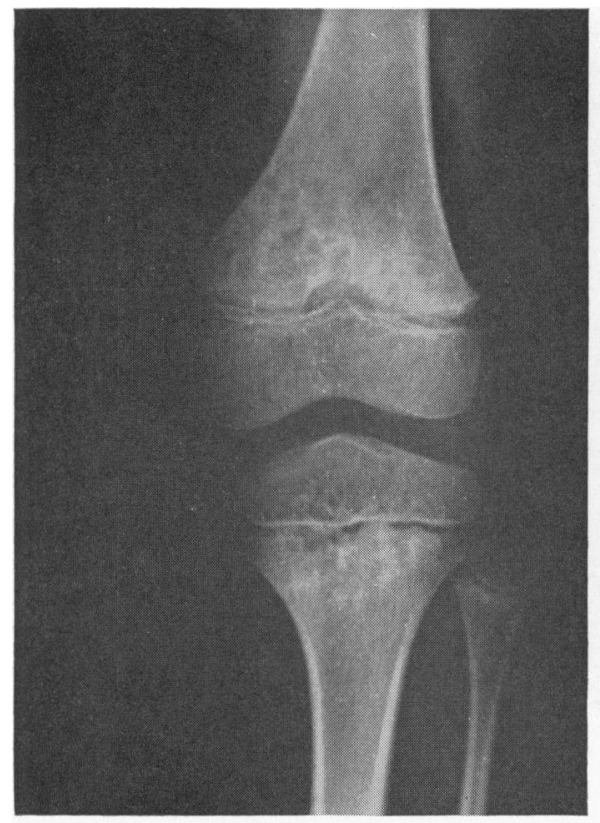

Fig. $1(a)$

at the time of bone-marrow biopsy was indicated by the reappearance of neutrophils in the peripheral blood soon after the aspiration. Case 5 later developed pancytopenia, and at this time hypoplasia of all bone-marrow elements was found.

Associated features. Irregular areas of varying density in the metaphyses of long bones, consistent with the radiological diagnosis of metaphysial dysostosis (Fig. 1a), were recognized in Case 5 at the age of 6 years. On reviewing his earlier radiographs, similar changes were seen to involve the anterior ends of the ribs at the age of 2 years. Radiographs of the long bones have been taken in all patients diagnosed since our recognition of this boy's bony abnormality, and the existing films have been reviewed in all other patients. It has not been possible to perform skeletal radiographs in the patients diagnosed early in the course of our investigation.

Irregularities of the anterior ends of the ribs were present in Case 5 in films taken at the age of 18 months, in Case 3 at the age of 2 years, and in Case 12 at the age of 3 months (Fig. 1b). No bony abnormalities were present in Case 10 which was the only other child to have a full radiological examination.

Family studies. Unfortunately these were limited. The father of Case 1 had mild neutropenia

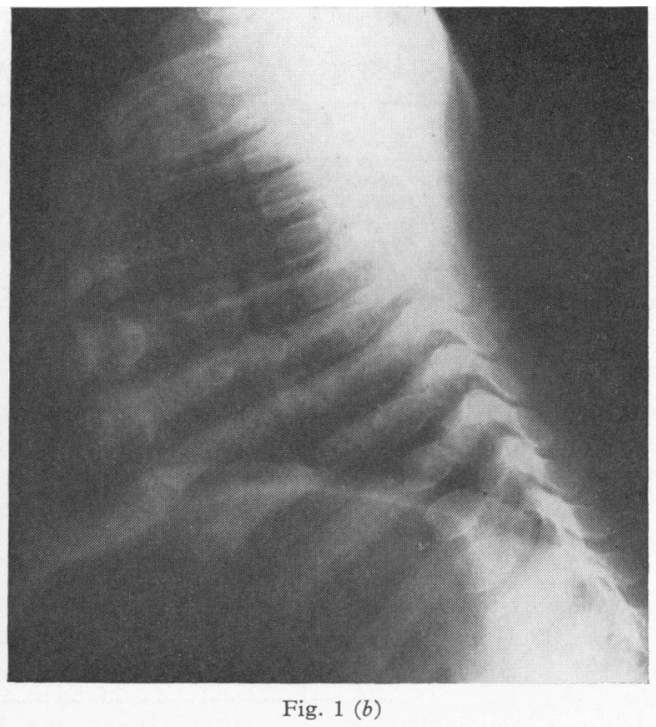

FIG. 1.-Irregularity of the (a) metaphyses in the tibia and femur of Case 5, and (b) the ribs of Case 11.

but the mother's white cell counts were normal. In the family with 3 affected children (Cases 2, 3, and 4) both parents and the fourth sib had normal white cell counts. Pancreatic enzyme activity was also normal in this child. The parents and brother of Case 10 had normal white cell counts but the only sister, who died in infancy with septicaemia, was known to have had neutropenia.

\section{Discussion}

The study of these patients has confirmed the association of neutropenia with pancreatic insufficiency. Although most children examined by us and shown to have steatorrhoea of pancreatic origin prove to have cystic fibrosis, there remains a small number of patients with normal levels of electrolytes in the sweat. Of this small group, this study reveals that the majority have associated haematological abnormalities, particularly chronic neutropenia, occasionally more generalized bone-marrow dysfunction, and some have associated bony metaphysial abnormalities as well. In our experience this combined syndrome has proved to be the most frequent condition in which pancreatic exocrine insufficiency occurs in children, apart from those suffering from cystic fibrosis.

Tests of pancreatic function in childhood have not received the attention given to the diagnosis of pancreatic disease in adults. Estimation of pancreatic enzyme activity in the duodenal contents, 
sometimes after the instillation of olive oil (Shwachman and Dooley, 1955), has been the basis for pancreatic function tests in children, developing from the methods used in the diagnosis of cystic fibrosis. Secretin-pancreozymin tests, with the measurement of the volume and bicarbonate content of the duodenal contents, have not been widely used in children, and normal values are not established. Thus, the diagnosis of pancreatic insufficiency in our patients, as in those of Shwachman et al. (1964), depended only on the demonstration of greatly reduced activity of pancreatic enzymes. Our results have been reproducible on samples obtained from the same patient on different occasions. In the 3 patients given intravenous secretin and pancreozymin, there was still no enzyme activity in the duodenal aspirate. Although our test may be less sensitive than the secretin-pancreozymin method, it seems reliable in separating patients with absence of pancreatic enzymes.

Normal levels of electrolytes in the sweat and the absence of chronic suppurative lung disease separate these children from patients with cystic fibrosis, but these 2 groups also differ in the symptoms of malabsorption. Our observations have confirmed those of Shwachman et al. (1964) that steatorrhoea in some patients with pancreatic insufficiency and neutropenia tends to be most severe in infancy. Two patients who initially presented with severe diarrhoea are now free of symptoms without requiring supplements of pancreatic extract, and in a third faecal fat excretion has decreased considerably. Although steatorrhoea is now less severe in these 3 children, pancreatic enzymes are still absent from the duodenal contents. This is in contrast to patients with cystic fibrosis whose steatorrhoea often persists even with the addition of pancreatic extract and does not improve with age. The explanation of this difference is obscure. Because the bowel symptoms may be minimal in older children with pancreatic insufficiency and neutropenia, this syndrome may not be obvious clinically. Of the neutropenic patients who were not initially suspected of having malabsorption and whose pancreatic function was investigated, 3 had no pancreatic enzymes. Steatorrhoea was present in all 3 but was minimal in 2 .

All 11 patients with pancreatic insufficiency and neutropenia had recurrent infections. Usually these were not severe, but one patient (Case 9) presented with meningitis and had recurrent pneumonia, another (Case 7) presented with mastoiditis followed by troublesome recurrent otorrhoea for several years, and a third (Case 5) died from severe chronic infections including empyema and liver abscess. Shwachman et al. (1964) reported that infections were not a problem in their patients, but the degree of neutropenia in them was generally less than in our patients.

Just as this combined syndrome may be overlooked in neutropenic patients whose bowel symptoms are minimal, so it may be overlooked in patients known to have malabsorption unless sufficient differential leucocyte counts are done. The total leucocyte count always fluctuates, sometimes over a very wide range, especially in patients with cyclical neutropenia. Infections may produce either a leucocytosis or a sudden increase of leucopenia, depending on circumstances. Moreover, in our cases neutrophil levels as low as $0-200$ / c.mm. were sometimes present with total leucocyte counts of $4000-7000 / \mathrm{c} . \mathrm{mm}$.; this was due to associated monocytosis and/or eosinophilia (both greater than 3000/c.mm. on occasions in Cases 6 and 7) and sometimes to lymphocytosis.

It follows that neutropenia may not be recognized unless both total and differential counts are performed sufficiently often. Our experience indicates that neutropenia cannot be definitely excluded unless these are done at least twice weekly for 3 weeks while the patient is free of infection.

Other haematological abnormalities were not as prominent in our series as in that of Shwachman et al. (1964). Thrombocytopenia was demonstrated in only 2 patients; in all others the platelets appeared plentiful in blood films, though platelet counts were not done. Hypochromic anaemia responding to iron was found in 7 patients. One patient (Case 5) developed marrow hypoplasia with severe pancytopenia in the blood following measles with bronchopneumonia; this responded to treatment which included prednisolone.

Hypocellularity of the bone-marrow involving the myeloid series and sometimes the megakaryocytes was described by Shwachman et al. (1964) in 5 of their 6 cases. In our 8 cases in which the bonemarrow was examined, the usual finding was a relative depression of the myeloid series with 'maturation arrest'; one with thrombocytopenia (Case 8) also had a decrease of megakaryocytes. In 2 of our cases, however, the bone-marrow appeared quite normal on examination during a phase of leucocytosis, illustrating the tendency for both marrow and blood findings to fluctuate in this condition.

Associated abnormalities were not reported in the cases described by Shwachman et al. (1964). We found radiological features of metaphysial dysostosis in 3 patients (Cases 5, 3, and 12), while Hirschsprung's disease also occurred in Case 5 and in a cousin of Cases 2, 3, and 4 . 
These associated features are of interest in relation to a recent report of patients with the cartilage hair hypoplasia syndrome (McKusick, Eldridge, Hostetler, Ruangwit, and Egeland, 1965). In all these children the radiological features of metaphysial dysostosis are present, while Hirschsprung's disease and malabsorption occur in some patients. On reviewing these patients, McKusick has found 3 with neutropenia, 2 having Hirschsprung's disease and the third pneumonia and malabsorption (V. A. McKusick, 1965, personal communication). Aregenerative anaemia and malabsorption occurring in another child have also been reported (Burgert, Dower, and Tauxe, 1965). The association of neutropenia and metaphysial dysostosis has also been recorded (Theodorou and Adams, 1963), but no comments were made concerning bowel symptoms. These reports suggest that there may be an association between pancreatic insufficiency, neutropenia, metaphysial dysostosis, and Hirschsprung's disease, which warrants further investigation. However, there is no obvious explanation for the association of such abnormalities.

A familial incidence of pancreatic insufficiency and bone-marrow dysfunction was noted by Shwachman et al. (1964) who reported this condition in 2 sibs. In our series, 3 sibs in one family (Cases 2,3 , and 4) were found to have both features while a fourth sib had normal pancreatic enzymes and neutrophil counts. Neutropenia was demonstrated in the father but not in the mother of Case 1; pancreatic function was not investigated. Case 10 had a neutropenic sib who died of septicaemia, but the other sib and both parents had normal white cell counts. These observations suggest that the syndrome of pancreatic insufficiency and neutropenia could be inherited, but no conclusion as to the mode of transmission is possible from these small numbers. The finding of neutropenia in a father and daughter appears to exclude intrauterine infection as the cause of this syndrome if the aetiology is the same in all patients.

Pancreatic biopsy was performed at the age of $6 \frac{1}{2}$ years in 1 of the patients described by Shwachman et al. (1964), in a 3-year-old and a 7-year-old described by Bodian et al. (1964), and in our own patient (Case 5) when he was $3 \frac{1}{2}$ years old. Fat replaced most of the acinar tissue in each of these patients but some acinae could be recognized. In the case described by the first authors, intranuclear inclusions were seen in the acinar cells. The pancreas was examined at necropsy in another of our patients (Case 10) who died at the age of 5 months. The major ducts were filled with hyaline material, but no changes could be seen in the exocrine tissue.
These observations could indicate that there is progressive degeneration of the pancreatic exocrine tissue. In several patients symptoms of malabsorption were not present at birth, and in 1 child (Case 6) did not appear until the age of 10 months. This clinical feature could also be explained by a progression of degenerative changes in the acinar tissue of these patients.

It seems unlikely that pancreatic exocrine insufficiency could be the cause of bone-marrow dysfunction. Patients with cystic fibrosis do not show neutropenia, and in patients with pancreatic insufficiency and neutropenia therapy with pancreatic extract does not affect the haematological findings.

It is clear that an association exists between bone-marrow dysfunction and pancreatic exocrine insufficiency, but the explanation of this association is obscure.

\section{Summary}

Eleven patients with the syndrome of pancreatic insufficiency and neutropenia are described.

Although this syndrome is rare, after excluding patients with cystic fibrosis, it appears to be the commonest cause of pancreatic insufficiency in childhood.

The association of neutropenia and pancreatic insufficiency may be overlooked. Neutropenia is often variable and leucocytosis occurs with infections. If frequent white cell counts are not performed when the patient is free from infection, neutropenia may not be apparent.

In these patients there is a tendency for steatorrhoea to diminish with time though pancreatic insufficiency is still demonstrable. Symptoms of malabsorption may, therefore, be minimal in older children. Thus, in children with idiopathic neutropenia, and perhaps in adults, pancreatic function should be investigated.

Metaphysial dysostosis and Hirschsprung's disease were present in some of the patients, suggesting that the syndrome is more complex.

A familial incidence was observed but, because of the small number of patients studied, suggestions regarding a mode of inheritance are not possible.

We thank the physicians who referred these patients for investigation. We acknowledge the assistance of technicians from the Haematology and Gastroenterology laboratories.

\section{REFERENCES}

Bodian, M., Sheldon, W., and Lightwood, R. (1964). Congenital hypoplasia of the exocrine pancreas. Acta paediat. (Uppsala), 53, 282. 
Burgert, E. O., Jr., Dower, J. C., and Tauxe, W. N. (1965). A new syndrome-aregenerative anemia, malabsorption (celiac), dyschondroplasia and hyperphosphataemia. F. Pediat., 67, 711.

Colebatch, J. H., Anderson, C. M., Simons, M. J., and Burke, V. (1965). Neutropenia and pancreatic disorder. Lancet, 2, 496.

Crosby, W. H., and Kugler, H. W. (1957). Intraluminal biopsy of the small intestine: the intestinal biopsy capsule. Amer. F. dig. Dis., $2,236$.

Free, A. H., and Myers, V. C. (1943). The estimation of the enzymes amylase, proteinase and lipase in duodenal contents. f. Lab. clin. Med., 28, 1387.

McKusick, V. A., Eldridge, R., Hostetler, J. A., Ruangwit, V., and Egeland, J. A. (1965). Dwarfism in the Amish. II Cartilagehair hypoplasia. Bull. fohns Hopk. Hosp., 116, 285.

Nothman, M. M., Pratt, T. D., and Benotti, J. (1948). The effect of the ligation of the pancreatic ducts and of pancreatectomy after duct ligation on serum lipase. F. Lab. clin Med., 33, 833.

Shwachman, H., Diamond, L. K., Oski, F. A., and Khaw, K. T. (1964). The syndrome of pancreatic insufficiency and bone marrow dysfunction. F. Pediat., 65, 645 .

- , and Dooley, R. R. (1955). Tests of exocrine functions of the pancreas in childhood. Pediat. Clin. N. Amer., 2, 201.

Theodorou, S. D., and Adams, J. (1963). An unusual case of metaphysial dysplasia. f. Bone $f_{t}$ Surg., 45B, 364.

Tomarelli, R. M., Charney, J., and Harding, M. L. (1949). Use of azoalbumin as a substrate in the colorimetric determination of peptic and tryptic activity. F. Lab. clin. Med., 34, 428.

Van de Kamer, J. H., ten Bokkel Huinink, H., and Weyers, H. A. (1949). Rapid method for the determination of fat in feces. f. biol. Chem., 177, 347.

\section{Appendix}

\section{Case Reports}

Case 1. A female, born at term in 1945 and weighing $2.5 \mathrm{~kg}$., presented at the age of 9 months for investigation of diarrhoea and poor weight gain which began after weaning 5 months before. There was no history of parental consanguinity. She had had several respiratory infections, and radiological examination of the chest on admission to hospital showed consolidation in the right upper lobe. Fat globules were seen on microscopy of the stools which contained $42 \%$ fat. A clinical diagnosis of cystic fibrosis was made and thought to be confirmed when no pancreatic enzymes were demonstrated in the duodenal contents. Weight gain followed the use of pancreatic extract and the stools became formed and less frequent.

Her progress was interrupted by frequent infections such as otitis media, tonsillitis, conjunctivitis, and pustular eruptions, and she was readmitted to hospital on two occasions because of acute bronchitis.

Neutropenia was first demonstrated at the age of 18 months when a blood examination was performed because of pallor. This showed a $\mathrm{Hb} 8 \mathrm{~g} . / 100 \mathrm{ml}$. and a white cell count of $7450 /$ c.mm., with 224 polymorphs/ c.mm. Treatment with iron orally was followed by a rise in haemoglobin but the neutropenia persisted. Folic acid therapy did not alter the neutrophil count. Bone-marrow biopsy showed a normal cell distribution A typical series of neutrophil counts (/c.mm.) was as follows: $5.8 .48,150 ; 8.8 .48,147 ; 9.8 .48,1072 ; 10.8 .48$, $960 ; 11.8 .48,1905 ; 12.8 .48,1239 ; 13.8 .48,1856$; $16.8 .48,1431 ; 19.8 .48,1003 ; 27.8 .48,371$.

Her father was found to have mild neutropenia while her mother had a normal neutrophil count.
When she was 12 years old the sweat test became available and normal sweat electrolyte levels were demonstrated.

She was examined recently at the age of 20 years and though infections are less frequent the neutropenia is still present. Pancreatic extract is still necessary to prevent diarrhoea. Height and weight are at the 10th centile.

Case 2. A female, born at term in 1954 after a normal pregnancy and weighing $3.5 \mathrm{~kg}$., presented at the age of 19 months for investigation of poor weight gain and diarrhoea. There was no parental consanguinity. Since birth the stools had been frequent, oily, and offensive, improving only when her paediatrician gave her pancreatic extract 3 months before admission. From the age of 6 weeks there had been recurrent upper respiratory tract infections and occasional episodes of bronchitis. At 19 months of age she was thin, but her abdomen was not distended and there were no signs or symptoms of chronic chest infection.

Fat globules were seen on microscopy of the stools and the average daily faecal fat excretion was $15 \mathrm{~g}$. $\mathrm{Hb}$ $11.6 \mathrm{~g} . / 100 \mathrm{ml}$. and white cell count $5250 / \mathrm{c} . \mathrm{mm}$., with 1575 neutrophils/c.mm. Sweat tests were not available for diagnosis of cystic fibrosis at that time and a duodenal intubation was performed. No trypsin, lipase, or amylase was found in the viscous fluid obtained, and she was considered to have cystic fibrosis. Treatment was continued with pancreatic extract and salt, and antibiotics were given for upper respiratory tract infections.

During the next 2 years respiratory infections were frequent, and at the age of $3 \frac{1}{2}$ years she developed a severe herpetic ulcerative stomatitis. While she was taking pancreatic extract the stools appeared normal. A sweat test performed at the age of $3 \frac{1}{2}$ years demonstrated normal electrolyte levels.

At the age of 6 she was admitted to hospital with measles, the only unusual features being the development of purpuric spots on the arms and bleeding from the gums. Full blood examination showed $\mathrm{Hb} 13.8 \mathrm{~g}$./100 ml., a total white cell count of $7600 / \mathrm{c} . \mathrm{mm}$., and 532 neutrophils/c.mm., and the platelets appeared normal. Faecal fat excretion was $10 \mathrm{~g}$. daily.

Respiratory infections became less frequent and, at the age of 8 , pancreatic extract was discontinued. The stools remained normal in appearance and weight gain continued.

With the recognition of the possible association between pancreatic insufficiency and neutropenia, this child was reinvestigated at the age of 11 years. Although she was below the 50th centile in weight and height, examination revealed no abnormalities. Duodenal intubation was repeated, and again no pancreatic enzymes were demonstrated.

Faecal fat estimations showed an average daily excretion of $5 \mathrm{~g}$. during 3 days. No fat globules were seen on microscopy of the stools. Repeated white cell counts (/c.mm.) confirmed the existence of neutropenia : 4.12.64, 2650; 7.12.64, 2290; 9.12.64, 752; 15.12.64, 846; $17.12 .64,624 ; 21.12 .64,2765 ; 28.12 .64,1935$. 
Case 3. The sister of Case 2 was born at 43 weeks' gestation after an uneventful pregnancy and weighed $3 \mathrm{~kg}$. Skin infections were troublesome until she was 6 months old, and from the age of 4 months she had recurrent upper respiratory tract infections. The stools were bulky, frequent, and offensive and her weight gain had been poor despite a good appetite. As her mother considered these symptoms to be the same as those of Case 2, she started this child on pancreatic extract from the age of 13 months and this resulted in improved weight gain and formed stools.

At the age of 15 months she was admitted to hospital for confirmation of the diagnosis. She was below the 50th centile in weight and height, had some abdominal distension, but no other abnormality. Fat globules were present in the stools which contained $20 \mathrm{~g}$. fat daily. A sweat test was normal but the duodenal contents contained no lipase, trypsin, or amylase. $\mathrm{Hb} 10 \cdot 7 \mathrm{~g}$., white cell count 5650/c.mm., with 1017 neutrophils/c.mm., and the platelets appeared normal.

Pancreatic extract was discontinued after 4 years of treatment, but there was no recurrence of diarrhoea.

This child was also reinvestigated at the age of 9 years, and again no pancreatic enzymes were found in the duodenal contents. Minimal steatorrhoea was present with an average daily faecal fat of $5 \mathrm{~g}$., and no fat globules were seen on microscopy of the stools. Repeated white cell counts demonstrated variable neutropenia: 4.12.64, 651; 7.12.64, 1170; 9.12.64, 700; $15.12 .64,810 ; 17.12 .64,834 ; 21.12 .64,878 ; 24.12 .64$, $1250 ; 28.12 .64,1075$.

Case 4. The brother of Cases 2 and 3 was born on November 12, 1963, at term after a normal pregnancy and weighed $3.4 \mathrm{~kg}$. His progress was similar to his sisters, and by the age of 6 months he was considered by his mother to have the same disease. Improvement in his weight gain followed treatment with pancreatic extract and the stools became normal in appearance. When investigated for the first time at 12 months of age he, like his sisters, was found to lack pancreatic enzymes in the duodenal contents. A sweat test was normal. Fat globules were present in the stools and there was an average daily faecal fat excretion of $12 \mathrm{~g}$. A series of neutrophil counts (/c.mm.) carried out in 1964 were as follows: 4.12.64, $140 ; 7.12 .64,621 ; 9.12 .64,810$; $15.12 .64,270 ; 17.12 .64,142 ; 21,12,64,792 ; 24.12 .64$, $300 ; 28.12 .64,220$.

The only other child in this family, a healthy female, born in 1955, has normal levels of pancreatic enzymes and is not neutropenic.

Case 5. A male was born prematurely in 1959, after an uneventful pregnancy, and weighed $2 \cdot 2 \mathrm{~kg}$. The father was Australian and the mother Anglo-Indian. $\mathrm{He}$ was presented to his doctor because of poor weight gain and vomiting at the age of 6 weeks. No diagnosis was made despite investigation, and symptoms continued. Abdominal distension and oily offensive stools were first noticed soon after weaning at the age of 6 months. Numerous fat globules were seen on microscopy of the stools. As there had been several mild respiratory infections a clinical diagnosis of cystic fibrosis was made and pancreatic extract was given. He then developed constipation and increased abdominal distension without improvement in weight gain.

He was not seen again by his doctor until the age of 15 months when he was wasted, with gross abdominal distension and many palpable faecal masses. He had been severely constipated and had frequent attacks of vomiting. Hirschsprung's disease was diagnosed when a rectal biopsy revealed the absence of ganglion cells.

Following a colostomy there was some gain in weight but the colostomy actions were loose and offensive. $\mathrm{He}$ was first referred to the Royal Children's Hospital, Melbourne, at the age of 2 years. He was below average in height and weight, with abdominal distension and a pigeon-chest deformity. The colostomy actions contained fat globules and the daily fat excretion was $10 \mathrm{~g}$. Pancreatic enzymes were absent from duodenal aspirate and a sweat test was normal. Full blood examination showed $\mathrm{Hb} 11.8 \mathrm{~g} . / 100 \mathrm{ml}$., white cell count $11,200 /$ c.mm., with 6600 neutrophils/c.mm., and normal platelets.

He was given pancreatic extract, resulting in firmer colostomy actions and improved weight gain. At the age of $3 \frac{1}{2}$ years recto-sigmoidectomy was performed and the colostomy closed. During this procedure a pancreatic biopsy was obtained. This showed fatty tissue containing normal islet cells, but no exocrine glands were seen.

At the age of 6 years, when a series of white cell counts were performed, cyclical neutropenia was demonstrated(neutrophils/c.mm.): 11.6.65, 702; 15.6.65, 1000; $16.6 .65,2146 ; 17.6 .65,1876 ; 18.6 .65,1395 ; 19.6 .65$, $2268 ; 22.6 .65,680 ; 25.6 .65,216 ; 27.6 .65,660 ; 29.6 .65$, 1505.

Platelet counts were low, varying between 30,000 and 100,000 during this period. Bone-marrow biopsy, performed during a period of leucocytosis, appeared normal. Stool microscopy showed cysts of Giardia lamblia and fat globules with a daily fat excretion of 15-24 g. A duodenal biopsy showed increased cellularity of the lamina propria and some blunting of the villi, changes that may have been related to the Giardia lamblia infestation. During this admission the radiological features of metaphysial dysostosis were recognized (Fig. 1a), and on review, were also found in earlier $x$-ray films. Initially these changes were most obvious in the ribs, but later involved the limbs. Serum calcium, phosphate, alkaline phosphatase, and protein were all normal.

Six months later he developed measles with pneumonia and a purpuric rash, and subsequently was pale and listless. Full blood examination now showed $\mathrm{Hb} 5 \cdot 4 \mathrm{~g}$./ $100 \mathrm{ml}$., white cell count 6700/c.mm. (polymorphs $1675 /$ c.mm.), and platelets 30,000 . As the serum iron was $44 \mu \mathrm{g}$., treatment was started with ferrous sulphate mixture. The reticulocyte count rose to only $4 \%$ and after 2 weeks the $\mathrm{Hb}$ was $7 \cdot 2 \mathrm{~g} . / 100 \mathrm{ml}$. but 2 weeks later had fallen to $5 \mathrm{~g}$. $/ 100 \mathrm{ml}$., with a reticulocyte count of $1 \cdot 2 \%$. The platelet count remained between 16,000 
and 35,000 and there was persistent neutropenia, the neutrophil count ranging from 290 to $1400 /$ c.mm. A bone-marrow aspiration showed hypoplasia of the myeloid and erythroid series with few megakaryocytes.

He was given a blood transfusion which increased the $\mathrm{Hb}$ to $12 \mathrm{~g} . / 100 \mathrm{ml}$. and treatment with prednisolone was started. Since then the haemoglobin has remained above $10 \mathrm{~g} . / 100 \mathrm{ml}$., and the platelet count has risen to above 100,000 . Variable neutropenia has persisted but at times neutrophil counts have been above $3000 /$ c.mm.

Case 6. A male, born in 1960 after a normal pregnancy and weighing $4 \mathrm{~kg}$., was first admitted to hospital at the age of 6 months with empyema. There was no parental consanguinity. $\mathrm{He}$ had had an infected umbilicus at the age of 1 week, a gluteal abscess at $2 \frac{1}{2}$ months, and a submandibular abscess at 4 months, each resolving in about 1 week with antibiotic therapy.

The empyema was treated by rib resection and drainage, and six weeks later he was discharged though the chest film still showed some opacity over the right upper lobe. Hb 11 g. $/ 100 \mathrm{ml}$., platelet count normal but neutrophils were only $275 / \mathrm{c} . \mathrm{mm}$. No bony abnormalities were found; bone-marrow biopsy showed myeloid depression and serum protein electrophoresis showed a total protein of $8.6 \mathrm{~g} . / 100 \mathrm{ml}$. with raised $\gamma$-globulin.

Two months later he was readmitted to hospital, with measles, skin pustules, and recurrence of empyema. Chronic neutropenia persisted and a typical series of white cell counts showed (/c.mm.): 2.9.61, 180;8.9.61, $480 ; 14.9 .61,1000 ; 15.9 .61,1000 ; 19.9 .61,160 ; 30.9 .61$, 350.

He was discharged home after 1 month's treatment with antibiotics, and during the next 18 months he required treatment only for skin infections. However, at the age of 2 years and 10 months empyema recurred requiring thoracotomy with intercostal drainage.

Three months later, at the age of 3 years and 1 month, he developed fever associated with right upper abdominal pain and was again admitted to hospital. He was found to have a liver abscess which was drained at laparotomy. Wound infection necessitated hospitalization for 3 months.

Three weeks after discharge fever recurred, associated with otitis media and an enlarged tender liver which was considered to be due to cholangitis. He responded slowly to antibiotics and was discharged home after 2 months.

He remained generally unwell with intermittent fever and failed to gain weight, and between this time and his death at the age of 4 years 10 months he was in and out of hospital with ulcerative stomatitis, gluteal abscesses, congestive cardiac failure, pneumonia, otitis media, and continuing drainage from the liver.

Pancreatic enzymes were absent from a specimen of duodenal contents obtained at the age of $4 \frac{1}{2}$ years. The average daily fat excretion was $3.5 \mathrm{~g}$. while the intake was only $25 \mathrm{~g}$., so that the fat absorption was $86 \%$.

Before death he became jaundiced, and angiograms demonstrated complete blockage of the right portal vein, with atrophy of the right lobe of the liver. At necropsy the pancreas appeared histologically normal.

Both parents had normal white cell counts. There was one normal female sib and the only other sib had been found dead in her cot at the age of 3 months.

Case 7. A male was born at term in 1959 after a normal pregnancy and weighed $3 \mathrm{~kg}$. There was no parental consanguinity. He first presented at the age of 13 months with mastoiditis. Repeated minor infections including conjunctivitis, skin pustules, and tonsillitis had been troublesome, and intermittent diarrhoea occurred from the age of 4 months. Neutropenia was found on his first hospital admission at the age of 13 months. Haemoglobin was $7 \cdot 8 \mathrm{~g} .100 \mathrm{ml}$. and platelets were normal. A bone-marrow biopsy showed myeloid depression.

Tonsillitis and otitis media recurred frequently, and chronic otorrhoea had been present since the episode of mastoiditis.

Although there had been several episodes of diarrhoea, the stools were not considered to be persistently abnormal but, on direct questioning, his mother thought that the stools were more bulky than those of his sib.

Duodenal intubation at 6 years of age showed absence of pancreatic enzymes. Fat balance demonstrated an average daily fat excretion of $6 \mathrm{~g}$., but no fat globules were seen on stool microscopy. Neutropenia has been confirmed on several occasions, usually associated with a mild anaemia. Platelets have always appeared normal. Neutrophil counts during a period of one week were as follows (/c.mm.): 22.7.64, 88; 24.7.64, $0 ; 27.7 .64,0$; 29.7.64, 65 .

Both parents and one sib have normal white cell counts.

Case 8. A female, born 3 weeks prematurely in 1961 and weighing $2 \mathrm{~kg}$., presented in the neonatal period with a staphylococcal enteritis. Recovery was slow, and even after this acute episode had subsided the stools appeared unusually loose and offensive. Pancreatic extract was used empirically during the first year, with improvement in the diarrhoea. However, her weight gain was poor and milestones were delayed. A sweat test was normal.

At the age of 13 months, routine full blood examination showed mild hypochromic microcytic anaemia with $\mathrm{Hb} 8.4 \mathrm{~g} . / 100 \mathrm{ml}$. and neutrophil count of $320 / \mathrm{c} . \mathrm{mm}$. $\mathrm{Hb}$ quickly rose to normal with oral iron therapy, but variable neutropenia persisted. During the next 3 years neutrophil counts, though performed too infrequently to establish any periodicity, ranged between 0 and 1145/ c.mm.

At 15 months she presented with purpura and the platelet count was found to be 1050 ; $\mathrm{Hb} 10 \mathrm{~g} . / 100 \mathrm{ml}$., and neutrophil count $1045 / \mathrm{c} . \mathrm{mm}$. A bone-marrow biopsy at this time showed hypoplasia of the myeloid and megakaryocyte series, and she was treated with prednisolone. Three months later the platelet count was normal, but two attempts to discontinue steroids 
were followed by a fall in the platelet count, so prednisolone has been continued.

Serum protein electrophoresis at the age of 18 months showed a normal pattern and a total protein of $7 \cdot 1 \mathrm{~g} . / 100$ $\mathrm{ml}$.

Her pancreatic function was not investigated until the age of 4 at which time she was mentally retarded and below the 10th centile in weight and height with moderate abdominal distension but no other abnormalities. Duodenal contents contained no pancreatic enzymes and fat globules were present in the stools. Daily faecal fat excretion was $12 \mathrm{~g}$. $X$-ray films of the long bones showed no abnormality.

There was no relevant family history.

Case 9. A male, born at term in 1963 after an uneventful pregnancy, weighed $2 \cdot 8 \mathrm{~kg}$. His only sib, a male, progressed normally. His maternal grandmother required splenectomy 10 years earlier because of thrombocytopenia, but we have been unable to study her. There was no parental consanguinity. He was first admitted to hospital with purulent meningitis and bilateral basal pneumonia at the age of 14 months. Since 2 months of age there had been frequent episodes of otitis media and tonsillitis, but his growth had been satisfactory until he was weaned at 10 months of age. $\mathrm{He}$ then began to lose weight and developed diarrhoea, the bowel actions having previously been normal in appearance except for periods of a few days coinciding with a temporary change to cows' milk feeds. On admission he appeared wasted, with marked abdominal distension. The meningitis quickly cleared, and other investigations then demonstrated steatorrhoea, with an average daily faecal fat excretion of $15 \mathrm{~g}$. Coeliac disease was suspected but a duodenal biopsy was not diagnostic, showing only mild blunting of the villi. Fat globules were seen in the stools, but a sweat test was normal. Duodenal intubation was planned, but his parents refused further investigation and he was allowed to go home. As his diarrhoea and steatorrhoea were less marked when milk was excluded, he was discharged on a milk-free diet.

During the first week at home he gained a little weight but then developed an ulcerative stomatitis and became extremely debilitated. When readmitted there was abdominal distension and scattered râles throughout the lung fields, with radiographic evidence of right lower lobe consolidation; he was started on penicillin and erythromycin. However, diarrhoea and poor weight gain persisted despite a milk-free diet, and steatorrhoea was severe (40 g./day). Intravenous therapy was required on 2 occasions. Pancreatic extract was given empirically, with some decrease in steatorrhoea. Duodenal intubation was performed on 2 occasions, the second time after stimulation with secretin and pancreozymin, but no pancreatic enzymes were detected on either occasion. Following this observation, neutropenia was sought, and the following are the neutrophil counts throughout his second stay in hospital, indicating a cyclic variation (/c.mm.): 5.10.64, 6890; 10.11.64, 1242; 27.11.64, 2346;
$3.12 .64,4687 ; 22.12 .64,470 ; 24.12 .64,432 ; 26.12 .64$, $385 ; 28.12 .64,1767 ; 30.12 .64,957$.

Pancreatic extract was continued and weight gain has improved and diarrhoea ceased. Since then his progress has been interrupted by several episodes of bronchitis, skin infections, and a non-suppurative arthritis of the knee. Serum protein electrophoresis has shown no abnormality.

Case 10. A female, born at term in 1965 after a normal pregnancy and weighing $2.8 \mathrm{~kg}$., was referred for investigation of poor weight gain and feeding difficulties at the age of 2 months. There was no parental consanguinity. She appeared microcephalic with severe mental retardation.

Routine investigations included full blood examination which showed $\mathrm{Hb} 13.4 \mathrm{~g} . / 100 \mathrm{ml}$., white cell count $9200 /$ c.mm., of which $184 /$ c.mm. were neutrophils, and platelets appeared normal. A series of white cell counts were then performed and persistent neutropenia was found (/c.mm.): 3.8.65, 184; 5.8.65, 128; 11.8.65, 0 ; 18.8.65, 35 .

Bone-marrow biopsy on August 9, 1965, showed myeloid depression with maturation arrest at the myelocyte level.

During this admission she had several apnoeic attacks, and there was chest infection, $x$-ray films showing patchy consolidation throughout the lung fields.

Duodenal intubation yielded scanty fluid containing only traces of lipase and amylase and no trypsin even after stimulation with secretin. No fat globules were seen on microscopy of the stools, and the average daily faecal fat excretion during a 3-day period was $3.5 \mathrm{~g}$. However, her daily intake of fat was only $20 \mathrm{~g}$., so that the fat absorption was $83 \%$. Sweat electrolytes were normal.

She continued to have chest infections and apnoeic attacks and died at 5 months of age. Necropsy showed inspissated secretion filling the ducts of the pancreas, but no other histological abnormality.

One female sib had had staphylococcal skin infections since birth, and died at the age of 2 months with staphylococcal septicaemia, pneumothorax, and bronchopneumonia. A complete absence of neutrophils and $\mathrm{Hb}$ $7.5 \mathrm{~g} . / 100 \mathrm{ml}$. was found the day before death. The pancreas was not examined at necropsy. White cell counts in both parents and the only surviving sib, a healthy male, were normal.

Case 11. A female infant, was born on October 2, 1965 , at 42 weeks' gestation, after an uneventful pregnancy and weighed $2.9 \mathrm{~kg}$. She was the only child of parents who were not blood relatives. During the first 3 weeks, while the baby was breast-fed, she appeared to progress normally. A cows' milk formula was introduced at the age of 3 weeks, and from this time she passed large offensive stools frequently. At the age of 4 months when she was referred for investigation she weighed only $3.8 \mathrm{~kg}$., and was a wasted pale infant with abdominal 
distension. The abnormal appearance of the stools was confirmed.

Fat balance studies during a period of 3 days showed an average daily excretion of $8 \mathrm{~g}$. fat, while the diet contained $25 \mathrm{~g}$. Fat globules were seen on microscopy of the stools. There was no trypsin, lipase, or amylase activity in specimens of duodenal contents.

Blood examinations established the presence of a variable neutropenia though there was a leucocytosis, with a total white cell count of about 15,000/c.mm. related to respiratory infections. Neutrophil counts (/c.mm.) were: 16.2.66, 1650; 1.3.66, 747; 17.3.66, 913;
24.3.66, 1240; 28.3.66, 2044; 30.3.66, 1800; 1.4.66, $1856 ; 4.4 .66,2000$.

$\mathrm{Hb}$ and platelet count were normal. Bone-marrow aspiration performed on March 30, 1966, showed no abnormality. Sweat electrolytes were normal. Radiological examination showed that the anterior ends of the ribs were wide and irregular (Fig. 1b). There were no changes seen on $x$-ray films of the long bones. Serum calcium, phosphorus, and alkaline phosphatase were normal. She was given pancreatic extract which controlled the diarrhoea, and improved weight gain followed. 